\title{
STUDIES OF HIGH- $\delta$ (BAFFLED) and LOW- $\delta$ (OPEN) PUMPED DIVERTOR OPERATION ON DIII-D
}

\author{
by \\ S.L. ALLEN, M.E. FENSTERMACHER, C.M. GREENFIELD, A.W. HYATT, \\ R. MAINGI, G.D. PORTER, M.R. WADE, A.S. BOZEK, R. ELLIS, \\ D.N. HILL, M.A. HOLLERBACH, C.J. LASNIER, A.W. LEONARD, \\ M.A. MAHDAVI, D.G. NILSON, T.W. PETRIE, M.J. SCHAFFER, J.P. SMITH, \\ R.D. STAMBAUGH, D.M. THOMAS, J.G. WATKINS, W.P. WEST, \\ D.G. WHYTE, and R.D. WOOD
}

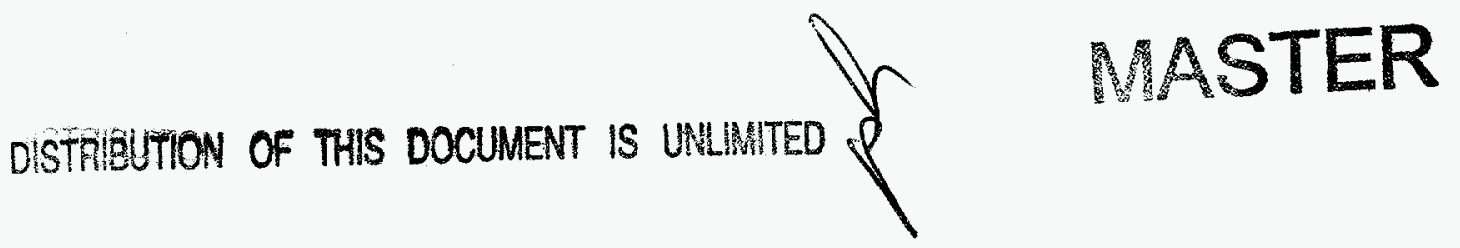




\section{DISCLAIMER}

This report was prepared as an account of work sponsored by an agency of the United States Government. Neither the United States Government nor any agency thereof, nor any of their employees, makes any warranty, express or implied, or assumes any legal liability or responsibility for the accuracy, completeness, or usefulness of any information, apparatus, product, or process disclosed, or represents that its use would not infringe privately owned rights. Reference herein to any specific commercial product, process, or service by trade name, trademark, manufacturer, or otherwise, does not necessarily constitute or imply its endorsement, recommendation, or favoring by the United States Government or any agency thereof. The views and opinions of authors expressed herein do not necessarily state or reflect those of the United States Government or any agency thereof. 


\section{DISCLAIMER}

Portions of this document may be illegible electronic image products. Images are produced from the best available original document. 
GA-A22878

\section{STUDIES OF HIGH- $\delta$ (BAFFLED) and LOW- $\delta$ (OPEN) PUMPED DIVERTOR OPERATION ON DIII-D}

by

S.L. ALLEN, ${ }^{\dagger}$ M.E. FENSTERMACHER, ${ }^{\dagger}$ C.M. GREENFIELD, A.W. HYATT,

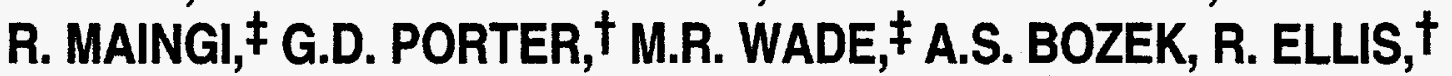
D.N. HILL, † M.A. HOLLERBACH, C.J. LASNIER, † A.W. LEONARD, M.A. MAHDAVI, D.G. NILSON, ${ }^{\dagger}$ T.W. PETRIE, M.J. SCHAFFER, J.P. SMITH, R.D. STAMBAUGH, D.M. THOMAS, J.G. WATKINS, $\diamond$ W.P. WEST, D.G. WHYTE, $\Delta$ and R.D. WOOD ${ }^{\dagger}$

This is a preprint of a paper to be presented at the 13th International Conference on Plasma Surface Interactions in Controlled Fusion Devices, May 18-23, 1998, San Diego, California and to be published in Journal of Nuclear Materials.

\footnotetext{
$\dagger_{\text {Lawrence Livermore National Laboratory }}$

¥Oakridge National Laboratory

$\checkmark$ Sandia National Laboratories, Albuquerque

$\triangle$ University of California, San Diego
}

Work supported by

the U.S. Department of Energy

under Contracts DE-AC03-89ER51114, W-7405-ENG-48, DE-AC05-96OR22464, DE-AC04-94AL85000, and Grant DE-FG03-95ER54294

GA PROJECT 3466 AUGUST 1998 


\begin{abstract}
We report new experimental results with the RDP-OB (Radiative Divertor Project-outer baffle) and cryopump in both upper single-null (USN) and double-null (DN) ELMing H-mode discharges. The baffled divertor reduced the core ionization $(\sim 2-2.5 \times)$, in reasonable agreement with predictions from UEDGE/DEGAS modeling $(\sim 3.75 \times)$. The upper cryopump achieved density control of $\mathrm{n}_{\mathrm{e}} / \mathrm{n}_{\mathrm{gw}} \sim 0.22$ (line density/Greenwald density) with $\mathrm{Z}_{\text {eff }} \sim 2$ in high- $\delta$ plasmas. The measured exhaust is comparable to the lower pump, except at lower core electron densities $\left(\mathrm{n}_{\mathrm{e}}<5 \times 10^{19} \mathrm{~m}^{-3}\right)$. Efficient impurity exhaust was obtained with deuterium SOL flow. Preliminary experiments with DN operation has shown that the particle exhaust to the upper pump depends on the up/down magnetic balance. Preliminary experiments indicate that the DN exhaust is roughly $40 \%-50 \%$ of the USN exhaust at $\mathrm{n}_{\mathrm{e}} \sim 4 \times 10^{19} \mathrm{~m}^{-3}$.
\end{abstract}


2 


\section{INTRODUCTION}

The main functions of a tokamak divertor are power exhaust with minimum damage to wall and divertor materials, and particle exhaust for the control of the density and impurities in the plasma core. Ideally, we would like to control the core and divertor plasmas separately, so that, for example, the divertor electron and ion temperatures $\left(T_{e}, T_{i}\right)$ are low to minimize sputtering while the core temperatures and energy confinement are high. As the power exhaust is usually concentrated in a small area, one currently-recognized technique of reducing the heat flux is dispersal with impurity radiation [1-3]. For this technique to be effective, radiating impurities must be concentrated in the divertor plasma (or scrape- off layer SOL plasma) but must not increase the core $Z_{\text {eff. }}$. The divertor $T_{e}$ and $n_{e}$ must be matched to the cooling rates of the chosen impurities to maximize the heat flux reduction. The plasma then "detaches" from material surfaces, but there must still be sufficient efflux to control the core density. All of these requirements may not be consistent and can compete in an overall divertor design.

Current "Advanced Tokamak" (AT) research $[4,5]$ has indicated that core plasma shape is important in optimizing the plasma pressure $\beta$ and confinement $\tau_{\mathrm{E}}$, which places an additional geometry constraint on the divertor. Experiments on the DIII-D tokamak at General Atomics have focused on several aspects of plasma shape, particularly high-triangularity $(\delta \sim 0.7)$ operation with both single-(SN) and double-null (DN) divertors [5]. The RDP is a phased plan of flexible divertor hardware and diagnostic installations designed to optimize both core and divertor performance. Recently, as part of the first phase RDP, we installed a new baffled divertor (which we will refer to as RDP-OB, for "outer baffle"), which is matched to these high- $\delta$ plasma shapes. With this installation and the flexible DII-D magnetic- coil set, we can compare plasma operation with: a) a baffled- high- $\delta$ SN divertor, b) an open high $\delta$ SN divertor, c) an open low- $\delta$ SN divertor, d) a baffled/open DN divertor, and e) an open DN divertor (by operating far away from the upper baffle).

The efficiency $(\eta)$ of radio-frequency (rf) current drive techniques (e.g. electron cyclotron current drive or ECCD) used to control the current profile in AT plasmas is proportional to $\eta$ $\mathrm{T}_{\mathrm{e}} / \mathrm{n}^{2}\left(5+\mathrm{Z}_{\mathrm{eff}}\right)$, so density and impurity control in high- $\delta$ shapes are important. Both divertors on DIII-D have liquid-helium cooled cryopumps, and the exhaust rate can varied by changing the strike point position. The pump exhaust can also be turned off by warming the cryopumps between shots. A new isoflux shape control system (which uses real-time calculated equilibria to control the plasma boundary) allows precise control of the divertor geometry and therefore exhaust during the discharge. The strikepoint location or $\mathrm{X}$-point is now controlled directly (previously, flux ratios from coils on each side of the $\mathrm{X}$-point were used to move the divertor 
plasma in and out). Real-time density control has been carried out using the strikepoint location (related to the exhaust rate) and gas puff rate as inputs to a control algorithm.

Modeling with the UEDGE/DEGAS [6,7] or UEDGE/EIRENE code has been used to guide the design of these divertor modifications. These codes have been benchmarked to data from DII-D plasmas in the open divertor, for which there is an extensive diagnostic set. We then calculated the effect of the closed divertor geometry on plasma quantities like the core ionization rate and estimated the optimum baffle width. Recent calculations have indicated that the divertor geometry can affect the plasma and impurity flows in the divertor, which could be used to concentrate impurities.

We present in this paper recent results from DIII-D operation with RDP-OB, along with comparisons to operation with the open lower divertor and cryopump. A comparison of plasma operation with baffled - versus open- divertors (high- $\delta \mathrm{SN}$ ) is the subject of Section 2, along with comparisons to the computational models. This is followed by a discussion of particle control in SN divertors in Section 3. Preliminary studies in DN operation have been carried out and are presented in Section 4, followed by a discussion and future plans. 


\section{COMPARISON OF BAFFLED- AND OPEN- DIVERTOR OPERATION (CRYOPUMP OFF)}

We have used the benchmarked UEDGE model of the edge plasma, along with Monte-Carlo neutrals calculations from DEGAS, to predict the reduction of the core ionization due to a more baffled divertor [8]. For this calculation, we have focused on the influence of the baffle; the cryopumps are not part of the calculation. Non-orthogonal grids were used to obtain the UEDGE plasma solution so that the recycling off of the slanted structures could be more accurately estimated. The actual divertor geometry was used in both the UEDGE and DEGAS models. Shown in Fig. 1 (top) is the hardware configuration for the full RDP (RDP-DN, for double-null) installation along with the DEGAS calculational grid. (The present installation RDP-OB uses only the outer baffle $O B$ in Fig. 1.) The position of the outer baffle (labeled OB in Fig. 1) was varied in the model and the core ionization current inside the separatrix was calculated. Shown in Fig. 1 (bottom) is the reduction in the core ionization $\mathrm{F}$ as a function of the baffle location $\mathrm{W}$. The width $\mathrm{W}$ is defined as the field line (mapped to the plasma midplane in $\mathrm{cm}$ ) that intersects the farthest projection (nose) of the outer baffle $O B$. The reduction factor $F$ is defined as the ratio of the calculated core ionization current to that of an open divertor with $W=11 \mathrm{~cm}$ (The ionization current was normalized to the plate current in the model). The model indicates that when $W<1.5 \mathrm{~cm}$, recycling is increased and this recycling can effectively penetrate into the plasma core, thereby reducing $\mathrm{F}$. When $\mathrm{W}>1.5 \mathrm{~cm}$, neutrals can leak around the divertor plasma and enter the plasma core at the midplane, again reducing $F$. The RDP design uses $W=1.5 \mathrm{~cm}$ as a baseline from these calculations.

The calculated $F$ for the present RDP installation RDP-OB is 3.75 for SN and 1.6 for DN plasma operation. As we have chosen to stage the installation, we have calculated $F$ for each of these phases. For the next phase, RDP-SN Baffle(RDP-SNB), the private flux space baffle (PB in Fig. 1) and inner wall baffle (IB) are added. We calculate $F$ for this case to be 9 (SN) and 1.8 (DN). For the full RDP-DN (upper and lower structures as shown in Fig. 1), F = 9 for both $\mathrm{SN}$ and DN plasma operation. Also note that the baffle shape is not parallel to the divertor flux lines for the base plasma case. The (heuristic) rationale for this choice is that recycling from the structure will be reintroduced back into the SOL onto field lines towards the separatrix, which should be desirable. Also, the upstream flat edge of the baffle--which can be a large recycling source - is farthest from the SOL plasma, limiting its effect on the plasma core. We are currently determining the validity of these assumptions with experiments where we vary the divertor flux expansion. 


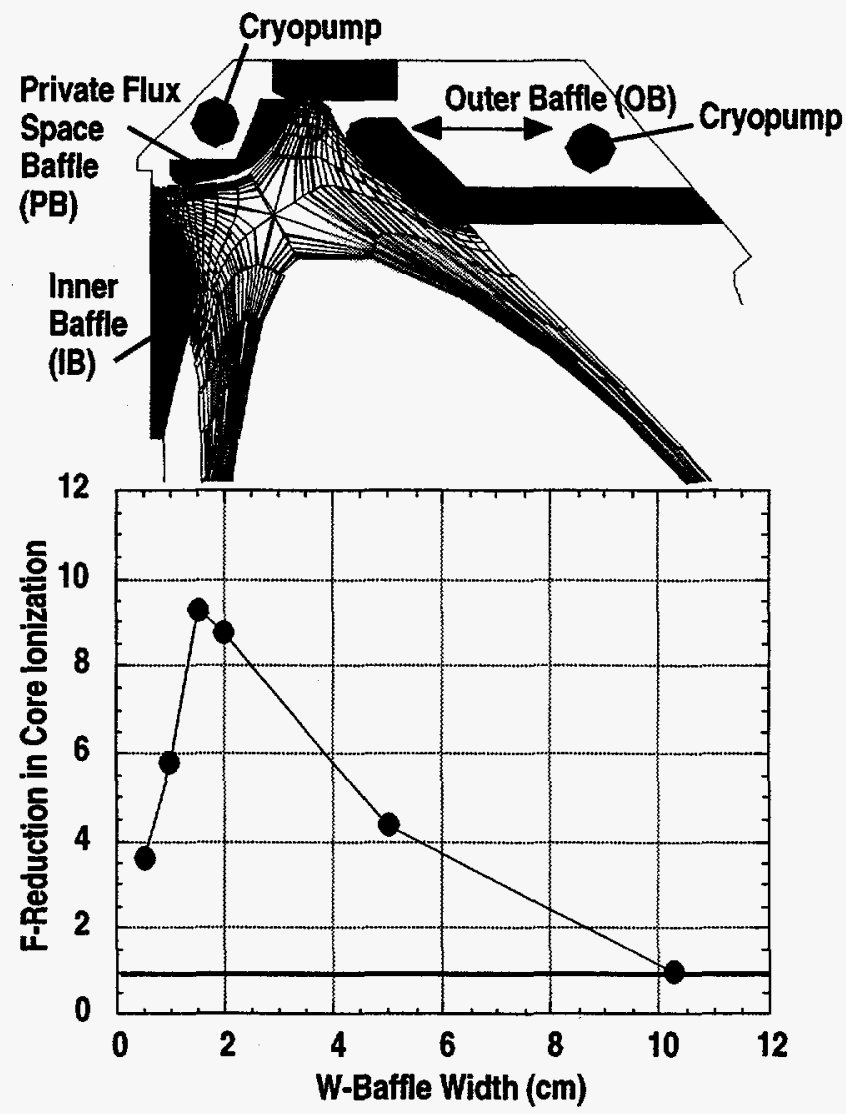

Fig. 1. Baffle "width" optimization from a UEDGE/DEGAS code calculation. The code was used with the actual geometry to determine the reduction in the core ionization (integrated inside the separatrix) as a function of the distance between the divertor strike point and the leading edge of the baffle. The reduction factor is predicted to be $F=9$ for the full $R D P$ (shown), and is 3.75 for $R D P-O B$, the present configuration.

Two specially- prepared similar plasmas were used for comparison: an (upper) SN-baffled (93866) and a (lower) SN-open (93743) high- $\delta$ discharge. These plasmas were nearly identical with those used in the UEDGE/DEGAS model calculations. The discharge parameters were: line average density $\mathrm{n}_{\mathrm{e}} \sim 6 \times 10^{20} \mathrm{~m}^{-3}$ (no gas puffing), plasma current $\mathrm{I}_{\mathrm{p}} \sim 1.5 \mathrm{MA}$, input neutral beam power $\mathrm{P}_{\mathrm{b}} \sim 6.6-7.2 \mathrm{MW}$, energy confinement $\tau_{\mathrm{E}} / \tau_{\mathrm{E}}(\mathrm{ITER}-89 \mathrm{P}) \sim 2$, and triangularity $\delta \sim$ 0.8 These were ELMing $\mathrm{H}-$ mode plasmas and the $\nabla \mathrm{B}$ drift direction was towards the active divertor plate in each case. To obtain $n_{e}$ and $T_{e}$ profiles with high spatial resolution in the SOL, the plasma shape was varied by $\sim 1 \mathrm{~cm}$ at the Thomson scattering measurement location to sweep the SOL plasma across the region of closely-spaced measurement channels. The other gaps between the plasma and material surfaces were controlled to be similar in the two shapes. These discharges were obtained with well-conditioned walls and discharge cleaning between shots.

We have estimated $F=2.6$, normalized to the plate current, from analysis of experimental data, in rough agreement with the model prediction. A qualitative measure of the reduction in 
core ionization is provided by an array of tangentially-viewing $\mathrm{H}_{\alpha}(6563 \AA)$ monitors at the plasma midplane; the signals in the baffled divertor case were decreased by a factor of 2 . As there are always concerns about interpreting $\mathrm{H}_{\alpha}$ data, a more quantitative comparison is provided by detailed analysis of the edge $n_{e}$ and $T_{e}$ profiles with a technique described in [9]. Briefly, hyperbolic tangent functions are used to fit the edge $n_{e}$ and $T_{e}$ profiles, and then transport analysis has been used to determine that the current crossing the separatrix $\mathrm{I}_{\perp} \propto \mathrm{D} / \chi \nabla \mathrm{n}_{\mathrm{e}}$, where the ratio of the heat conductivity $(2.5 \chi)$ to the diffusion coefficient $D$ is found to be 0.6 . For the baffled case, the measured pedestal density and density gradient are decreased, and the edge temperature gradient is increased. This analysis indicates that the ionization crossing the separatrix for the open divertor case $I_{\perp}=840 \mathrm{~A}$ (Amperes, equivalent particle current), as compared with $I_{\perp}=420 \mathrm{~A}$ in the baffled divertor, or a factor of 2 . Integrating the total number of electrons in the plasma, we also obtain roughly a factor of 2 decrease. To make a direct comparison with the model prediction (which is normalized to the current at the plate), we have corrected the data for the difference in the recycling current at the divertor plate, which is 1.3 from calibrated divertor photodiodes, or a total factor of 2.6. While there are uncertainties in the experimental determination of $\mathrm{F}$, the general trend of reducing $\mathrm{F}$ with the baffled divertor is evident, even at these modest values. In a more baffled divertor (RDP-SNB), $F$ is estimated to be 9, so better code comparisons should be possible. We also plan to vary the baffle width $\mathrm{W}$ as in Fig. 1 to determine if the measured optimum agrees with the code prediction.

We observed that the plasma transitions to the partially detached divertor (PDD) state at a $20 \%$ lower density in the baffled divertor, in agreement with other experiments. However, we did not find any strong dependence of the energy confinement time $\tau_{\mathrm{E}}$ on baffling. The measured $\tau_{\mathrm{E}}$ for a series of baffled vs. open discharges agreed to within $20 \%$; the scatter could be explained by slight differences in the MHD behavior of the discharges in the dataset. Our dataset was not large enough to make any further quantitative conclusions. In general, the dependence of $\tau_{\mathrm{E}}$ on $I_{\perp}$ or neutral pressure is not well understood from DIII-D data. In ELMing H-mode, we have observed [10] the $\mathrm{H}$-factor $\tau_{\mathrm{E}} / \tau_{\mathrm{E}}$ (ITER-89P) tends to increase from 1.2 to 2.2 as the private flux region pressure varies from $100 \mathrm{mT}$ orr to $0.1 \mathrm{mT}$ Trr (i.e., three orders of magnitude), suggesting that $\tau_{\mathrm{E}}$ increases as the pressure decreases. The scatter in this relationship is large, as $\mathrm{H}$ varies from 1.4 to 2.2 as the private region pressure varies between 0.1-1 mTorr. Also, most of the high-confinement (ELM-free) $\mathrm{H}$-mode operation usually occurs at a private flux pressure of $\sim 0.1-0.3$ mTorr. However, PDD operation with $\mathrm{H}=1.8$ is possible with a private flux pressure of 10 's of mTorr, which is not consistent with these data. Evidently, the changes in the neutrals made by the baffles has so far not been in a regime that significantly affects the confinement. 


\section{COMPARISON OF PARTICLE CONTROL IN BAFFLED- VS. OPEN- PUMPED DIVERTOR OPERATION (SN)}

\subsection{DEUTERIUM EXHAUST AND DENSITY CONTROL IN SN PLASMAS}

Liquid-helium cooled cryopumps are connected to both divertors to provide particle exhaust. The pump design and operating parameters are described in [11]. The measured deuterium pumping speed of the upper (lower) pumping system is $S_{u p}=40 \mathrm{k} \mathrm{ls}^{-1}\left(\mathrm{~S}_{\text {low }}=35 \mathrm{k} \mathrm{ls}^{-1}\right)$. The pumping speed varies only slightly over the length of the discharge, and the variation is less than uncertainties in other contributions to the overall particle balance. The pump exhaust $\mathrm{I}_{\mathrm{ex}}$ is the product of the pumping speed $S$ times the neutral pressure in the pump plenum $P_{p}$, which is measured by a fast time response neutral pressure gauge [12].

Previous experiments with the lower cryopump have shown that $I_{e x}$ can be increased (decreased) by decreasing (increasing) the distance between the separatrix and the pump aperture, and we have obtained the same qualitative behavior with the upper pump and baffle [13]. Figure 2 compares the plenum pressure $P_{p}$ as a function of the major radius of the strike point $R_{\text {sep }}$ for the a) upper and $b$ ) lower divertors in an ELMing $H$-mode plasma at a lineaverage density of $5-6 \times 10^{19} \mathrm{~m}^{-3}$. These curves were obtained with the pumps off so that the relationship between $P_{p}$ and $R_{\text {sep }}$ can be obtained at constant core plasma density. The data points were obtained by a strike point sweep in a single discharge, which explains the "trajectory" nature of the plots. From an operational standpoint, it is useful to compare the $P_{p}$ versus $R_{\text {sep }}$ directly, as this is related to how accurately the control system must control $R_{\text {sep }}$ to obtain a particular $\mathrm{I}_{\mathrm{ex}}$. It also determines the range of divertor configurations that can be obtained with a required $I_{e x}$. From Fig. 2, the measured $P_{p}$ decreases by a factor of 2 in about $6-7 \mathrm{~cm}$ for both the upper and lower divertor pumping configurations. For more general divertor design, we must determine this relationship as a function of flux geometry, which is the subject of future experiments.

The relationship between $P_{p}$ and $R_{\text {sep }}$ on DIII-D can be understood by a simple analytic model due to Maingi [14]; other models have also been developed [15]. The measured incident particle flux profile for a particular plasma condition and divertor geometry is obtained by sweeping the plasma across Langmuir probes in the aperture of the pump plenum. At a given separatrix location, the particle source at the pumping plenum and hence $P_{p}$ depends on a geometric solid angle factor and the probability that the particle will reach the plenum before it ionizes in the divertor plasma. The measured $n_{e}$ and $T_{e}$ from the Langmuir probe is used to estimate the ionization probability. This model reproduces the curves in Fig. 2 reasonably well. 

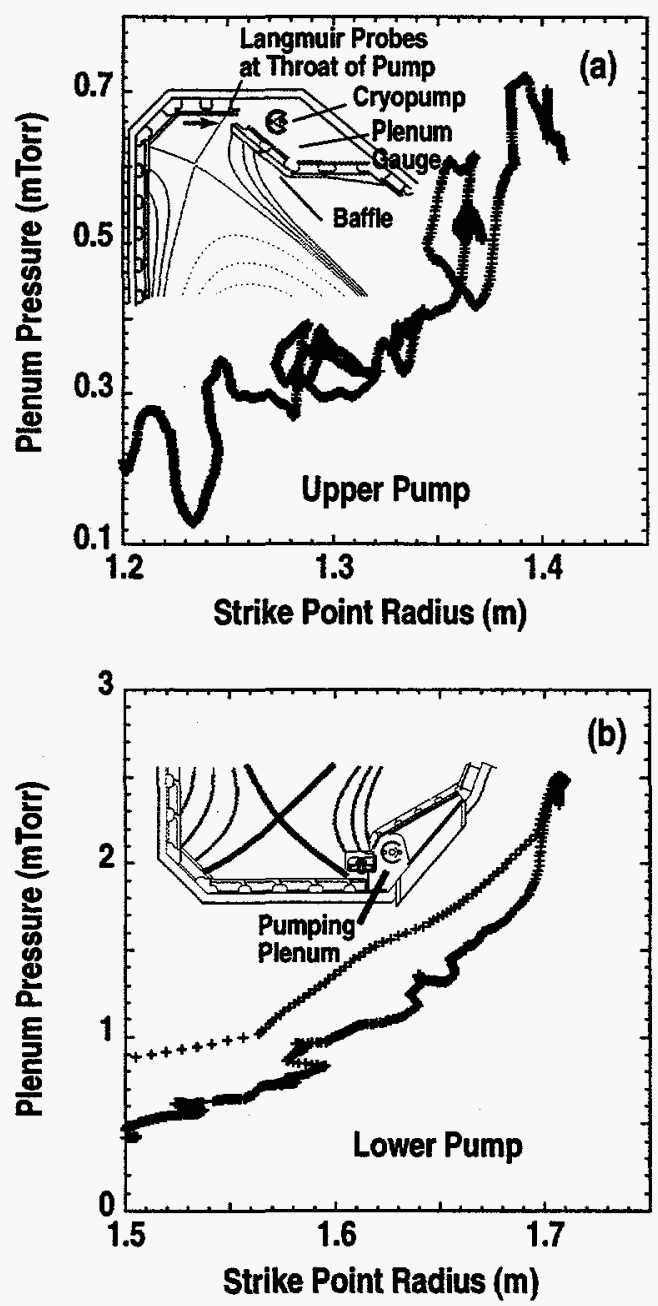

Fig. 2. A comparison of the plenum pressure $P_{p}$ as a function of the separatrix location for the (a) upper and ( $b$ lower divertors. These data were obtained with the pumps warm (i.e. constant density of 5-6 $\times 10^{19} \mathrm{~m}^{-3}$ ) and are a trajectory during an ELMing $H$-mode discharge.

Both the upper and lower divertors have been effective in reducing the core plasma density to similar steady-state values at the same plasma current; the actual value depends on the plasma current. In SN ELMing DIII-D plasmas, the core "natural" H-mode line-density scales with the plasma current. We can express this relationship in terms of a fraction of the "Greenwald density", $\mathrm{n}_{\mathrm{e}} / \mathrm{n}_{\mathrm{gw}} \equiv \mathrm{n}_{\mathrm{e}} / \mathrm{I}_{\mathrm{p}}\left(\pi \mathrm{a}^{2}\right)$. For operation without gas puffing, $\mathrm{n}_{\mathrm{e}} / \mathrm{n}_{\mathrm{gw}} \sim 0.5$. In low- $\delta$ operation with the lower pump, $\mathrm{n}_{\mathrm{e}} / \mathrm{n}_{\mathrm{gw}} \sim 0.22$ has been achieved [16]. In high- $\delta$ operation with the upper pump, $\mathrm{n}_{\mathrm{e}} \mathrm{n}_{\mathrm{gw}} \sim 0.27$ was the lowest value. At these densities, particularly with the lower pump, locked MHD modes appear which limit the operation. Error-correction coils have been used to obtain these low density values.

Dynamic density control during the discharge was also demonstrated, as shown in Fig. 3 which presents data from operation with the upper pump; the density figure of merit and $\mathbf{R}_{\text {sep }}$ 


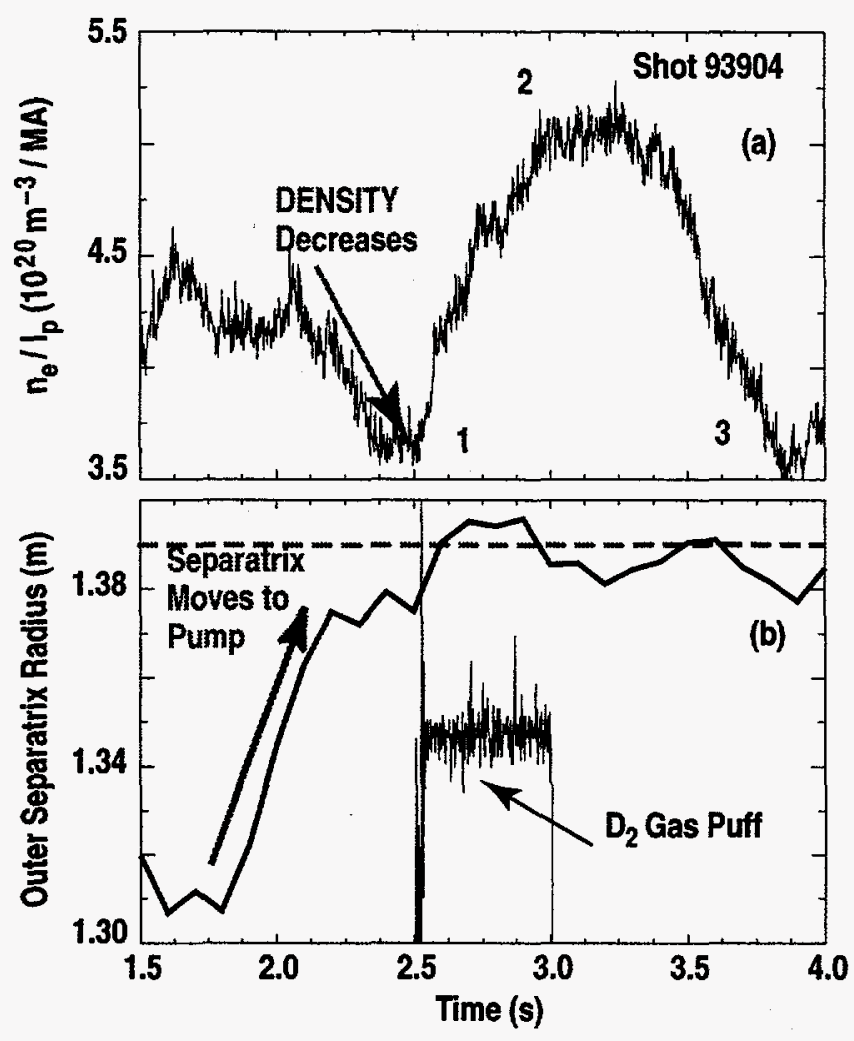

Fig. 3. The density normalized to the plasma current versus time for an ELMing $H$-mode discharge, note three times: (1) the strike point is swept towards the pump and the density decreases, (2) a deuterium gas puff is introduced and the density rises, and (3) after the gas puff, the density again decreases.

are shown as a function of time. As the strike point is moved towards the pump, the core linedensity decreases (the plasma current was held constant during the discharge) until a large gas puff $\left(100 \mathrm{~T} \ell / \mathrm{s}^{-1}\right)$ is introduced at $2.5 \mathrm{~s}$. The density rises in response to the gas puff and then decreases when the gas flow is stopped. The radial profiles of (core) $T_{e}$ and $n_{e}$ at the three times noted in Fig. 3 are compared in Fig. 4. The overall shape of the profiles remains roughly constant and the temperature increases as the density decreases, which is similar to operation with the lower pump. We are currently performing detailed analyses of the edge pedestal quantities (with more data outside of $\rho \sim 0.85$ ) to determine if they change during pumping.

The exhaust rate of both pumps is a strong function of density; preliminary data from the upper pump is compared with previous data for the lower pump as shown in Fig. 5. The data for the lower pump is from [17], careful sweeps of the strike point were used to measure the peak exhaust rate as a function of density; gas puffing was used to obtain the density scan. For the lower divertor, $P_{e x}$ scales as $n^{3}$ (line density); with $n^{2}$ of this dependence due to the observed relationship between the divertor and midplane densities. The upper divertor data was not obtained at the maximum pumping location, as the strike point was fixed at about $3 \mathrm{~cm}\left(\mathrm{R}_{\mathrm{sep}}=\right.$ 


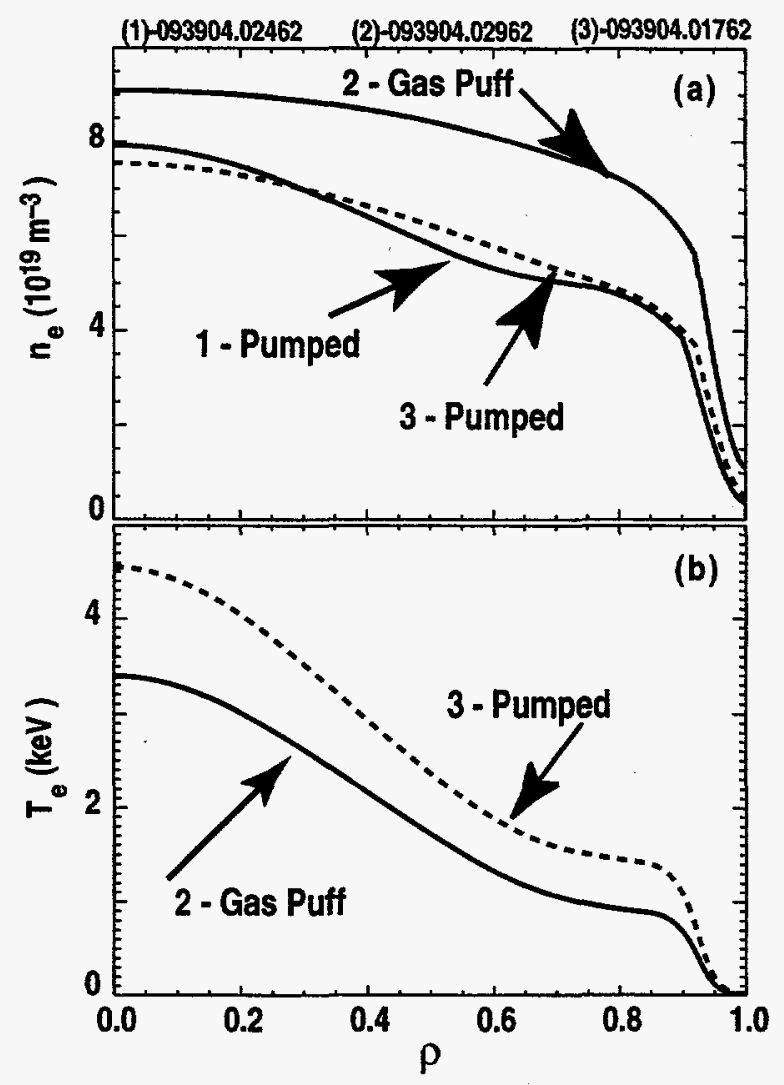

Fig. 4. The (a) electron density $n_{e}$ and (b) electron temperature $T_{e}$ profiles from Thomson Scattering for the three times in Fig. 4. The main features of the profile are similar in each case.

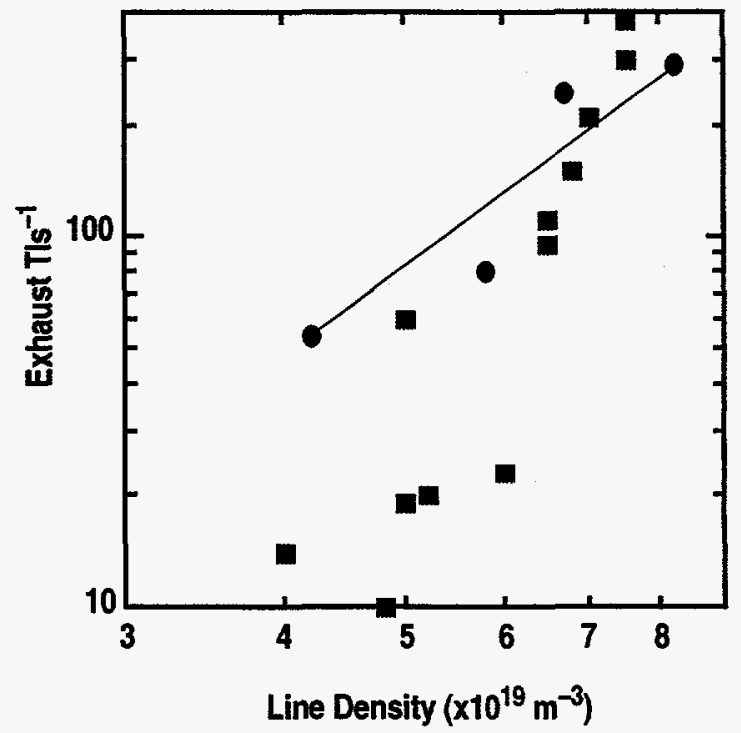

Fig. 5. Comparison of the pump exhaust as a function of line-average density. The solid circles are the peak exhaust rate for the lower pump [17], the squares are the exhaust rate for the RDP-OB at about $3 \mathrm{~cm}$ from the pump aperture. Note the decrease in the exhaust at low densities for the RDP-OB. 
$1.36 \mathrm{~m}$ ) from the pump aperture. (i.e., this is not the maximum exhaust rate, but is representative of this fixed strike point location). Nevertheless, there are trends in the data: 1) The exhaust rate $I_{\text {exh }}$ is roughly similar for the two pumps at $n_{e}>6 \times 10^{19} \mathrm{~m}^{-3}$, and 2) $I_{e x h}$ for the upper pump drops off sharply at $\mathrm{n}_{\mathrm{e}}<5 \times 10^{19} \mathrm{~m}^{-3}$ (additional data points for the upper pump with $\mathrm{n}_{\mathrm{e}}=4$ $\times 10^{19} \mathrm{~m}^{-3}$ show that the maximum exhaust is $\sim 15 \mathrm{~A}$, which is less than the lower pump). While definitive conclusions cannot be drawn from these preliminary data, it should be noted that there may be differences in the particle exhaust at low $n_{e}$ in the two cases due to ELMs (which depend on triangularity) or flux expansion. It also suggests that an optimum divertor design may depend on the divertor operational regime, and hence the density.

\subsection{IMPURITY EXHAUST AND “PUFF AND PUMP” RADIATIVE DIVERTOR EXPERIMENTS}

Impurity measurements during the RDP-OB experiments have shown that the impurity densities remain constant as $n_{\mathrm{e}}$ decreases, with $\mathrm{Z}_{\mathrm{eff}} \sim 2.0$ at $\mathrm{n}_{\mathrm{e}} / \mathrm{n}_{\mathrm{gw}}=0.27$. At the highest plasma current, $Z_{\text {eff }} \sim 2.5\left(I_{p}=2 \mathrm{MA}, 9 \mathrm{MW}\right.$ neutral beam input). We have obtained carbon, nitrogen, and oxygen densities with charge-exchange recombination (CER) measurements from the core "CER" system and the core SPRED spectrometer. The sum of these measurements are in agreement with $Z_{\text {eff }}$ obtained from a visible bremsstrahlung array. The principle impurity is carbon, which contributes an increase in $Z_{\text {eff }}$ of roughly $0.8-1$ for a 2 MA discharge. Oxygen and nitrogen impurities are more variable, and are more quickly reduced by plasma shots and discharge cleaning. Trace injection of neon at showed pumpout times were long at $n_{e}=4 \times 10^{19}$ $\mathrm{m}^{-3}$, consistent with the low deuterium exhaust reported above.

Our preliminary work with "puff and pump" (deuterium upstream puffing with divertor exhaust to influence SOL flow) experiments with the RDP-OB has been encouraging. In the trace impurity puffing experiments, we measured the decay of core argon charge-exchange emissions (SPRED) $\tau_{\mathrm{i}}$ in four cases of deuterium puffing: 1) divertor at $80 \mathrm{~T} \ell \mathrm{s}^{-1}($ i.e. we would

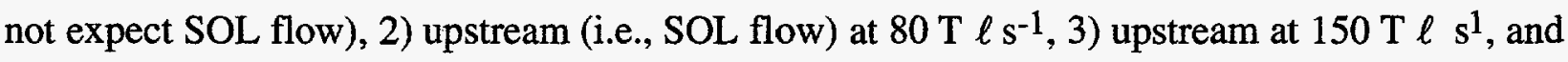
4) upstream at $230 \mathrm{~T} \ell \mathrm{s}^{-1}$. The measured $\tau_{\mathrm{i}}$ decreased from case 1 to 3 , consistent with a picture that increasing SOL flow exhausts argon. Under the conditions of case $3, \tau_{\mathbf{i}}$ was reduced to the point that it was comparable to $\tau_{\mathrm{E}}$. As expected, no further decrease was observed in case 4 . 
14 


\section{PARTICLE CONTROL IN HIGH- $\delta$ DOUBLE NULL PLASMAS}

We have observed a dependence of $I_{\text {exh }}$ from the upper pump on the up/down magnetic "balance" of a DN high- $\delta$ plasma. The measured $I_{\text {exh }}$ from the upper pump versus $d_{\text {rsep }}$, the distance between the upper and lower separatrices measured at the midplane, is presented in Fig. 6; the $\nabla B$ drift was upwards or towards (away) from the upper (lower) divertor. These data were ELMing $\mathrm{H}$-mode plasmas obtained with the pump cold, and therefore each point is at a slightly different density ranging from 3.8 (at the largest positive $d_{\text {rsep}}$ ) to $4.3 \times 10^{19} \mathrm{~m}^{-3}$ (at the smallest $d_{\text {rsep }}$ )--recall the $n^{3}$ dependence to $I_{\text {exh }}$ in Fig. 5 . The corresponding plasma shapes are shown in the Figure, note that $d_{\text {rsep }}=5.0 \mathrm{~cm}$ is nearly an USN plasma, and in this case $I_{\text {exh }}$ is roughly equivalent $(\sim 15 \mathrm{~A})$ to the low-density USN values shown in Fig. 5. The data indicates that for a range of about $1 \mathrm{~cm}<\mathrm{d}_{\text {rsep }}<4 \mathrm{~cm}$, the DN exhaust is roughly constant and about $50 \%$ of the SN value. To date, we have not tried to further optimize exhaust in DN operation, which may be possible. As we will discuss below, additional pumps should increase the exhaust for DN operation.

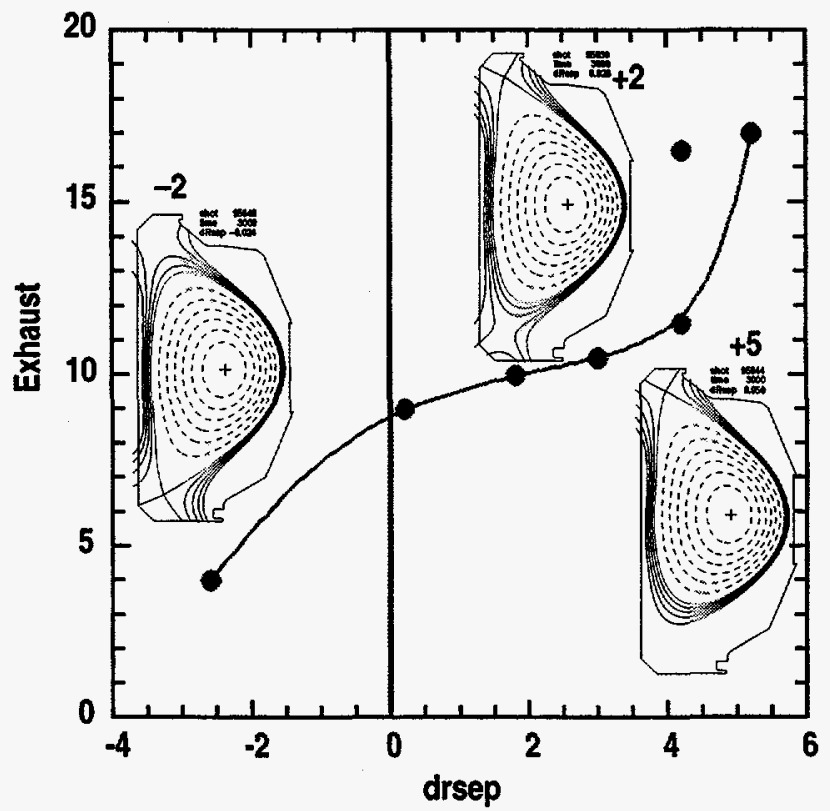

Fig. 6. The exhaust for the RDP-OB upper pump as a function of the magnetic balance ( $d_{r s e p}$ is the distance between the upper and lower null measured at the midplane) at a density of $3.8-4.3 \times 10^{19} \mathrm{~m}^{-3} . A d_{r s e p}$ of $5 \mathrm{~cm}$ corresponds to an USN and the exhaust is similar to that shown in Fig. 5 above. The exhaust for the DN case is about $50 \%$ of the USN with the single RDP-OB pump. 
16 


\section{DISCUSSION}

We have demonstrated a reduction in the measured core ionization with the baffled divertor (RDP-OB) of a factor of 2 . As the measured plate current differed by a factor of 1.3 in these two cases, the normalized reduction is $F=2.6$. The UEDGE/DEGAS modeling, (with ionization current normalized to the plate current) predicted $\mathrm{F}=3.75$, in reasonable agreement with the data. No changes in energy confinement were observed, but the density at which the PDD occurred was decreased by $20 \%$. Density control with $n_{e} / n_{g w}=0.27$ was achieved, which is similar to the 0.22 achieved in the lower pump. The particle exhaust of the upper pump is similar to the lower pump, except at low $\mathrm{n}_{\mathrm{e}}<5 \times 10^{19} \mathrm{~m}^{-3}$. Wall conditioning has controlled impurities in the baffled divertor so that $Z_{\text {eff }} \sim 2$; this increased to 2.5 at $I_{p}=2.0 \mathrm{MA}$.

To date, most of our work with RDP-OB has focused on USN operation with the $\nabla B$ drift towards the upper divertor plate. We will examine during the next campaign the importance of the $\nabla \mathrm{B}$ drift (i.e., the direction of toroidal field) on these results. We will also focus on increasing the exhaust of RDP-OB at low density, which may involve changing the contour of the outer baffle or the size of the pump aperture. Either change can be easily accomplished by installing a new set of carbon tiles on the water-cooled support plates.

In 1999, we plan to install a private flux space baffle, inner baffle, and cryopump for the inner strike point. Code predictions indicate that the reduction in the core ionization should be 9 in SN. Recent work with the UEDGE code [18] has also indicated that divertor geometry may play a role in plasma flows, and modeling will be used to guide the design of RDP-SNB. 
18 


\section{REFERENCES}

[1] H.-S. Bosch, D. Coster, R. Dux, et al., J. Nucl. Mater. 220-222 (1997) 82.

[2] S.L. Allen, N.H. Brooks, R.B. Campbell, et al., J. Nucl. Mater. 220-222 (1995) 336.

[3] R. Parker, G. Janeschitz, H.D. Pacher, et al., J. Nucl. Mater. 220-222 (1997) 1-26.

[4] T. Taylor, "Physics of Advanced Tokamaks," to be published in Plasma Physics and Controlled Fusion, 1998 (invited paper from 24th EPS Conference, Berchtesgaden, Germany, June 9-13, 1997).

[5] V.S. Chan, in Controlled Fusion and Plasma Physics 1996 (Proc. 16th Int. Conf. Montreal, Canada, 1995), Vol. 1, IAEA, (1997) 9.

[6] G.D. Porter, S.L. Allen, M. Brown, et al., Phys. Plasma 3, (1996) 1967.

[7] G.D. Porter, S.L. Allen, M.E. Fenstermacher, et al., in 23rd European Physical Society Conference on Controlled Fusion and Plasma Physics, Kiev, Ukraine, 1996.

[8] M.E. Fenstermacher, G.D. Porter, M.E. Rensink, et al., J. Nucl. Mater. 220-222 (1995) 330.

[9] G.D. Porter, M. Shimada, M. Sugihara, et al., "Analysis of Separatrix Plasma Parameters," this conference.

[10] R. Maingi, in DIII-D 5-Year Program Plan, in press, 1998.

[11] M.M. Menon, et al., Fusion Technology 27 (1995) 355.

[12] D. Colchin, et al., this conference.

[13] C.C. Klepper, J.T. Hogan, D.N. Hill, et al., Nucl. Fusion 33 (1993) 533.

[14] R. Maingi, J.G. Watkins, private communications, "Pump Plenum Dependence on Divertor Plasma Parameters and Magnetic Geometry on DIII-D,” D3DPM\#9802, March, 1998.

[15] A. Loarte, J.K. Ehrenberg, L.D. Horton, et al., in Controlled Fusion and Plasma Physics (Proc. 24th Eur. Conf. Berchtesgaden, 1997), Vol. 21A, Part III, (European Physical Society, Geneva, 1997) 1049.

[16] R. Maingi, et al., Nucl. Fusion 36 (1996) 245.

[17] M.J. Schaffer, R. Maingi, A.W. Hyatt, et al., Nucl. Fusion 36 (1996) 495.

[18] N. Wolf, et al., "Effect of Divertor Geometry on Plasma Detachment on DIII-D," this conferfence. 
$\gamma$ 


\section{ACKNOWLEDGMENTS}

This work was made possible by a large number technical personnel that designed and installed the RDP-OB hardware. The DIII-D operations team ensured the divertor and tokamak hardware were ready for experiments, and that the plasma control system could achieve the desired shapes. The AT+D Task Force planned, executed and analyzed the data from the experiments. Work supported by U.S. Department of Energy under Contracts DE-AC0389ER51114, DE-AC05-96OR22464, W-7405-ENG-48, DE-AC04-94AL85000, and Grant DEFG03-95ER54294. 